\title{
СОСТАВ ДИСТИЛЛЯТОВ КОКСОВАНИЯ ВЫСОКОКИПЯЩИХ ФРАКЦИЙ ЭСТОНСКОЙ СЛАНЦЕВОЙ СМОЛЫ
}

\section{Сообщение 1. Состав дефенолированных дистиллятов}

В последние годы в сланцеперерабатывающей промышленности освоен процесс коксования высококипящих фракций сланцевых смол с получением электродного кокса в качестве одного из основных продуктов. В процессе коксования смола подвергается глубоким термическим превращениям, в результате чего образуется твердый концентраг углерода - кокс - и летучие продукты - газ и дистил.тя, относительно обогащениые водородом. Поскольку дистиллят составляет, например, при коксовании остатка атмосферной дистилляции генераторной смолы до $2 / 3$ от сырья, то, естественно, что от ег квалифицированного использования в значительной степени зависит вся экономика процесса.

До сих пор, однако, состав дистиллятов коксования изучен явно недостаточно. Показано лишь, что по общей физико-химической характеристике они похожи на первичные смолы, несмотря на то, что состоят в основном из продуктов вторичного тер. мического разложения высококипящих фракций смолы и содержат только небольшое количество более низкокипящих фракций коксуемого сырья, перегоняіщихся в условиях коксования без разложения. В отличие от первинных сланцевых смол, дистиллять коксования содержат относительно меньше олефинов и нейтральных кислородных соединений $\left[{ }^{1}\right]$. Из индивидуальных соединений в дистиллятах идентифицированы некоторые водорастворимые алкилрезорцины $\left[{ }^{2}\right]$.

Целью настоящей работы было более подробное исследование состава дистиллятов коксования, полученных при различных режимах коксования. В статье приводятся результаты исследования всех составляющих химические группы соединений дистиллятов, за исключением фенолов, данные о составе которых опубликованы отдельно [ $\left.{ }^{3}\right]$.

\section{Методика}

Анализ проводился по схеме, примененной нами уже и ранее при исследовании состава смол полукоксования твердых топлив [4,5]. Исследованные пробы разделяли на группы соединений с помощью жидкостной хроматографии в колонках. Для дополнительного разделения применялась препаративная тонкослойная хроматография с последующим га зохроматографическим анализом выделенных структурных групп и про. граммированием температуры колонки [6]. Для анализа использовалась колонка длиной $6 \mu$ и диаметром 6-4 мм с $5 \%$ апиезона $L$ на хромосорбе W (45-60 меш).

Для дополнительной характеристики дистиллятов коксования применялась также четкая ректификация.

Общая характеристика исследуемых проб. В настоя. щей работе подробно были исследованы два образца дистиллятов, полученных при коксовании остатка атмосферной дистилляции генераторных 


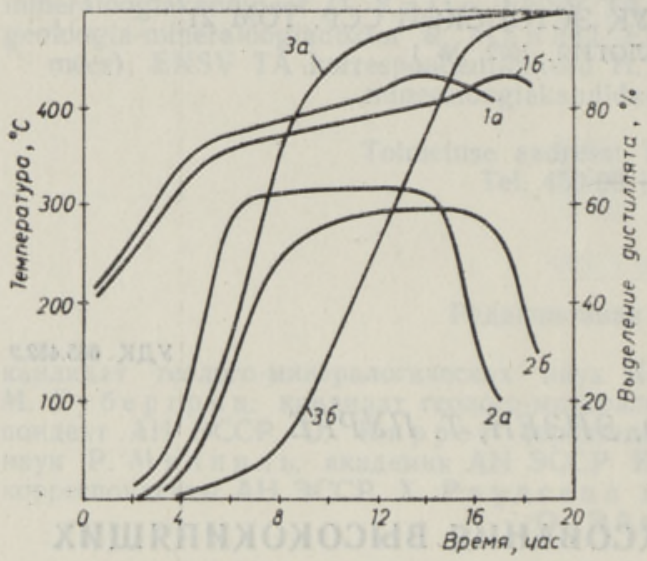

Рис. 1. Температурный режим коксования и выделение дистиллята.

$a$ - обычный режим коксования, б - коксование в кубе с дефлегмацией. Температура: 1 - в жндкой фазе, 2 - в парах; выход дистиллята - 3 смол на промышленной кубовой установке Сланцеперерабатывающего комбината им. В. И. Ленина в Кохтла-Ярве*. Один из образцов получен при обычном режиме коксования, второй при болсе глубоком разложении коксуемого сырья, что было достигнуто путем возвращения тя желой части дистиллята с помощью дефлегматора обратно в куб на повторное коксование. Метод предложен Н. Зелениным и В. Файнбергом [7] для повышения выхода кокса из сырья.

Температурные режимы коксования, а также динамика выделения дистиллята представлены на рис. 1. Видно, что процесс образования кокса проходит при

\section{Характерные данные дистиллятов коксования и исходного сырья}

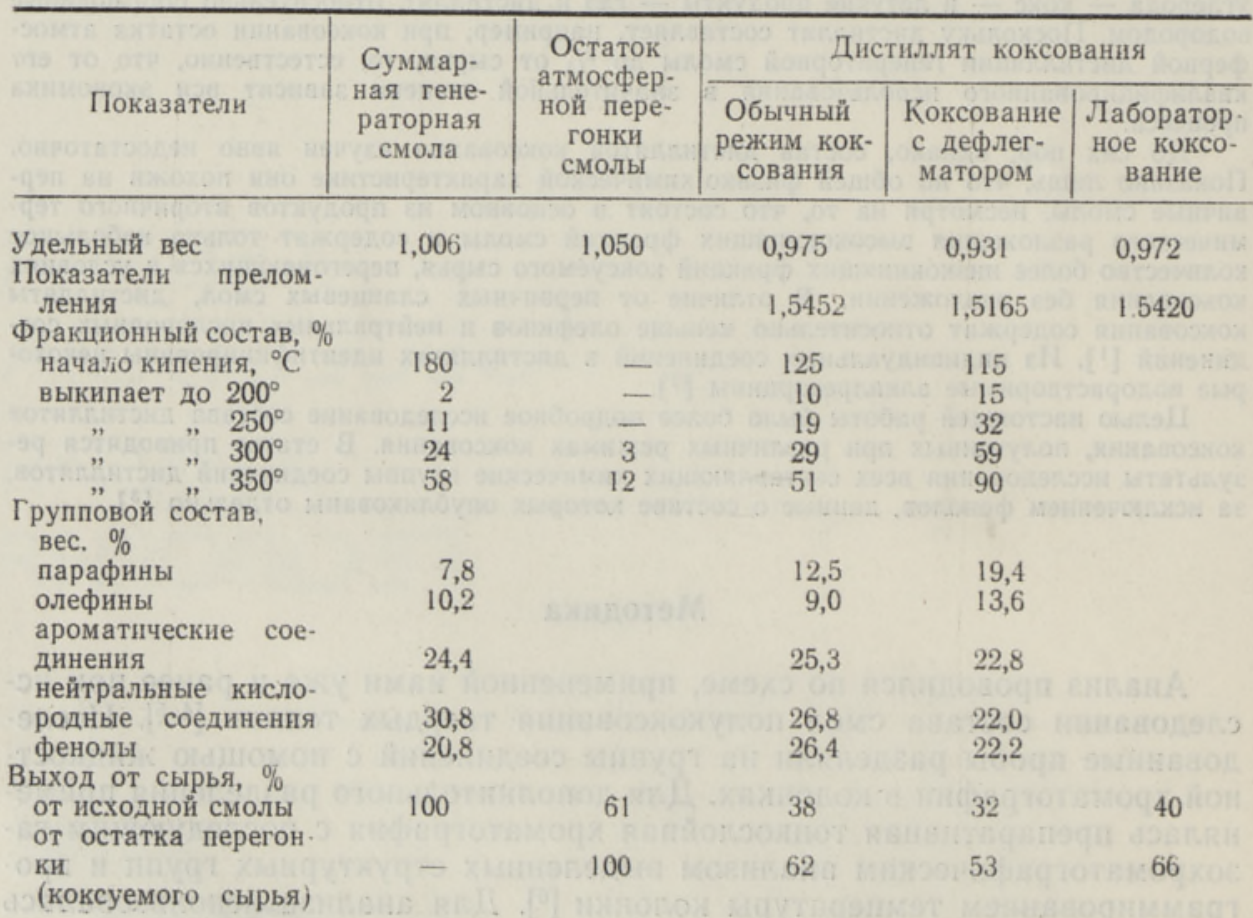

относительно низких температурах - в конце процесса температура в средней части коксового пирога лишь немного превышает $400^{\circ} \mathrm{C}$.

Выходы и некоторые физико-химические показатели сырья и дистиллятов коксования приведены в таблице. Для сравнения приведена характеристика исходной суммарной генераторной смолы.

4. В проведении промышленных опытов коксования принимал участие К. Р. Эйги. 
Дистилляты коксования охарактеризованы также по узким фракциям, полученным ректификацией $1,5 \Omega$ пробы на лабораторной колонке длиной $1,75 \mu$, диаметром 28 мм при остаточном давлении в пределах 50-1 мм рт. ст. Данные, характеризующие полученные фракции, представлены на рис. 2.

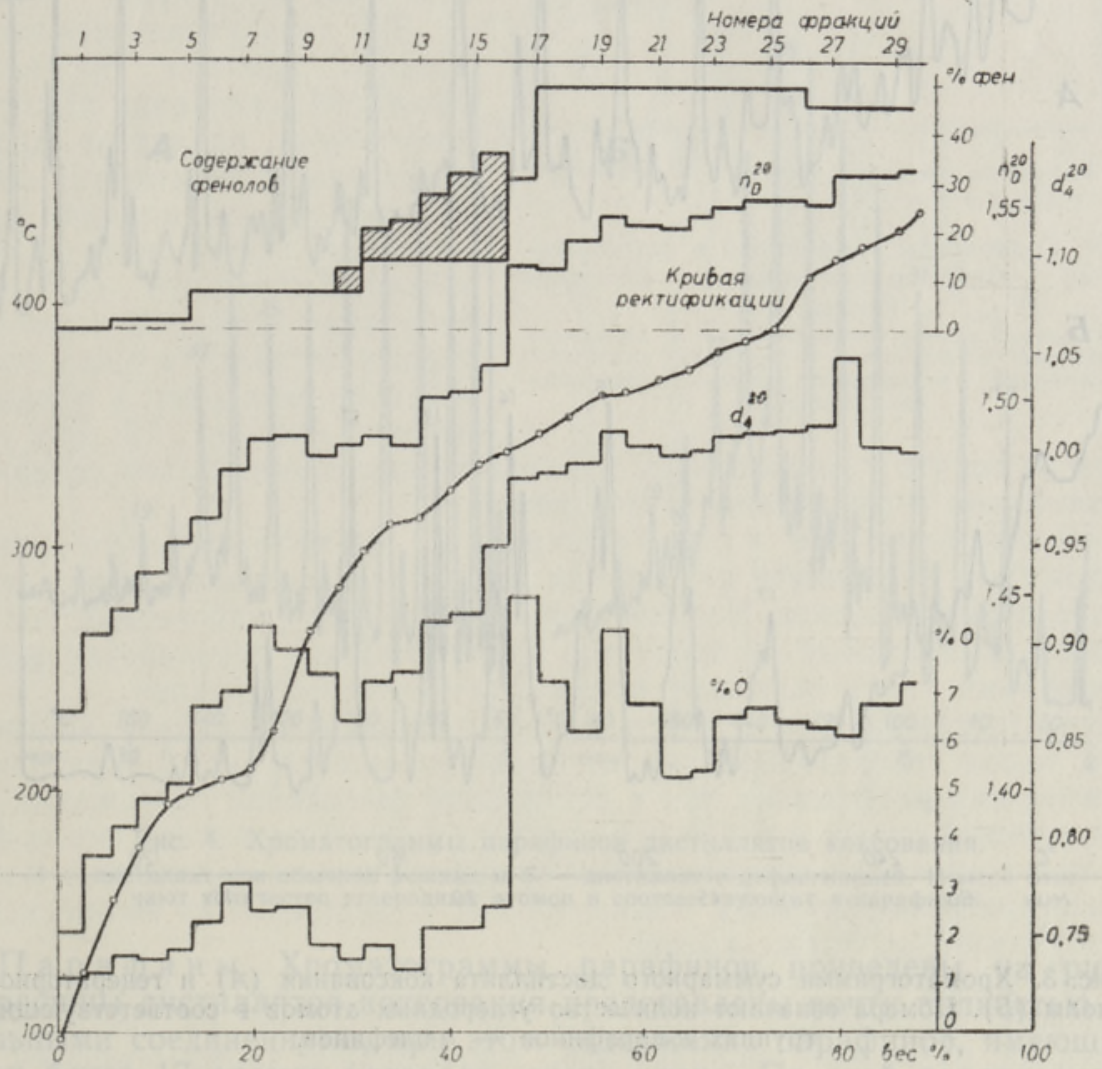

Рис. 2. Кривая ректификации дистиллята коксования ( $d=0,931$; с дефлегмацией) и данные, характеризующие фракции. Температуры кипения пересчитаны на атмосферное давление. Заштрихованная часть при содержании фенолов - фенолы, нерастворимые во фракциях. При определении кислорода названные фенолы не учтены.

Сравнение данных ректификации двух дистиллятов показалф, что рецикл тяжелой части дистиллята из дефлегматора в куб существенно увеличивает количество низкокипящих фракций, состоящих в основном из алифатических углеводородов, и снижает выход высококипящих кислородных соединений. С повышением температуры кипения выше $320^{\circ}$ резко возрастает содержание кислорода во фракцияпх, Резкое повышение содержания кислорода наблюдается также и в случае первичных сланцевых смол [8, 9], но уже при $280^{\circ}$.

Из-за малого содержания нейтральных кислородных соединений во фракциях дистиллята, выкипающих в пределах $270-320^{\circ}$, они не способны полностью растворять двухатомные фенолы и последние частично выпадают (на рис. 2 они отмечены штриховкой). Следует отметить, что количество выпадающих фенолов больше, чем при ректификации 


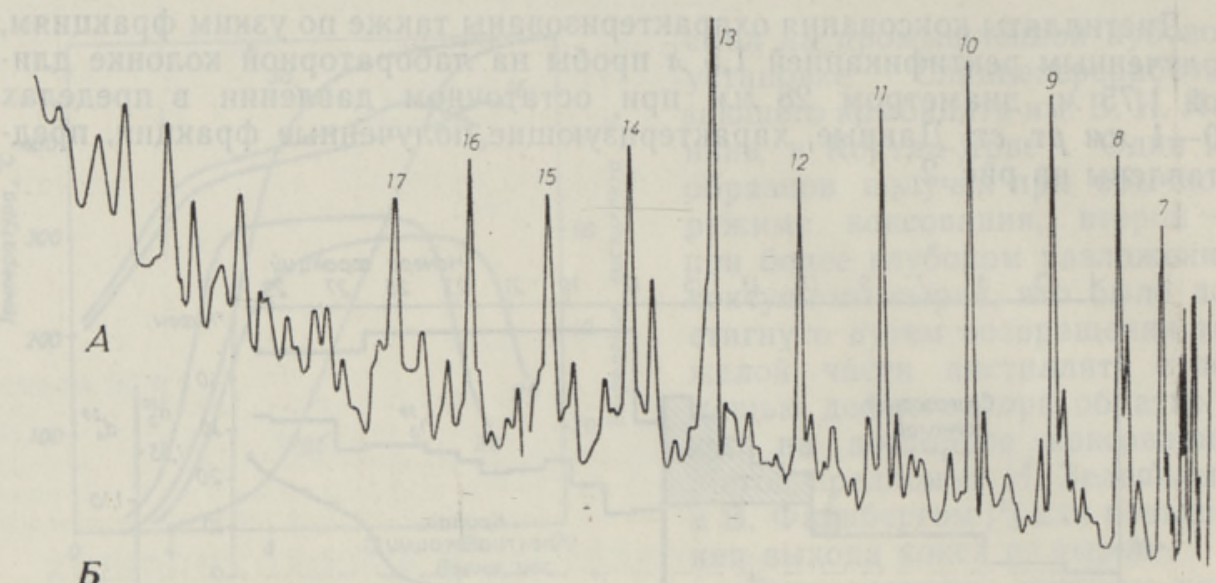

B

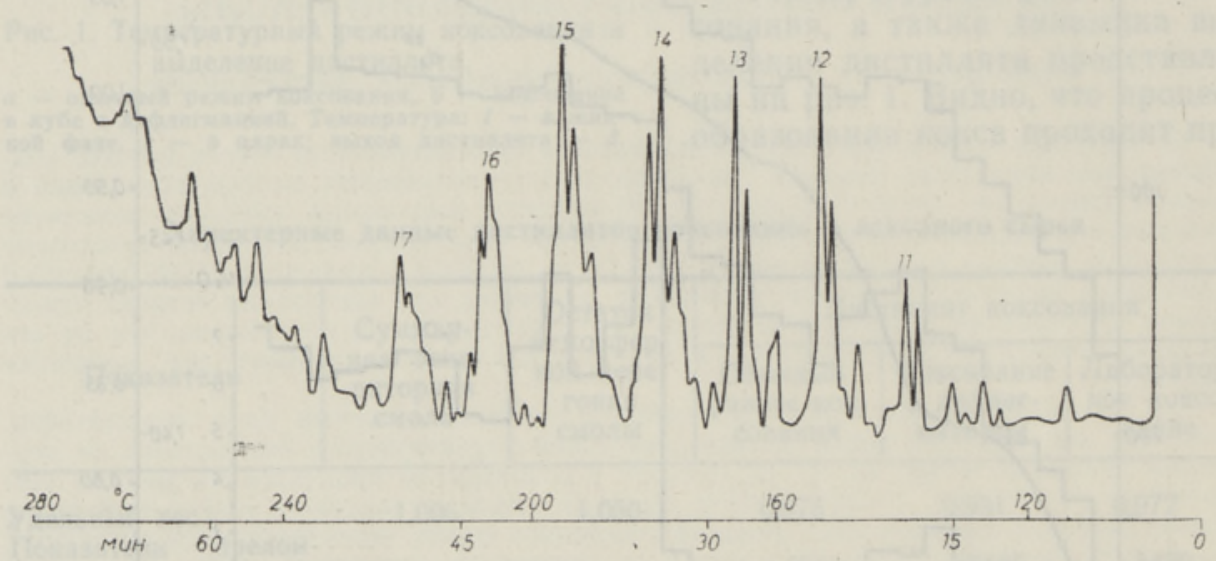

Рис. 3. Хроматограмма суммарного дистиллята коксования $(A)$ и генераторной смолы $(Б)$. Номера означают количество углеродных атомов в соответствующих группах $н$-парафннов -

первичных смол [8, 9]. Во фракциях выше $320^{\circ}$ отмечено появление кристаллического осадка.

Суммарные дистилляты подвергались также газохроматографическому анализу. Хроматограммы обоих дистиллятов мало отличаются друг от друга. На рис. 3 представлены хроматограмма одного дистнл лята коксования и хроматограмма суммарной генераторной смолы для сравнения.

Начальную часть хроматограммы характеризуют только пики нормальных соединений, а в конечной части из-за наличия большого количества кислородных соединений хроматограмма становится более слож. ной. Хроматограмма генераторной смолы в целом сложнее, так как некоторые группы пиков не разделяются.

Небезынтересно отметить, что, хотя коксуемое сырье - остаток дистилляции смолы - содержит неболышое количество фракций, перегоняемых в условиях дистилляции по Энглеру, при газохроматографическом аналнзе никаких пиков он не дает. Отсюда можно сделать вывод, что все компоненты, идентифицированные тем же методом в дистилляте коксования, являются продуктами термического разложения тяжелой сланцевой смолы. 


\section{Анализ групп соединений}

Из дистиллятов и суммарной генераторной смолы фенолы были выделены $10 \%$-ным раствором едкого натра. Нейтральные смолы анализировались дальше хроматографическими методами, как описано выше.

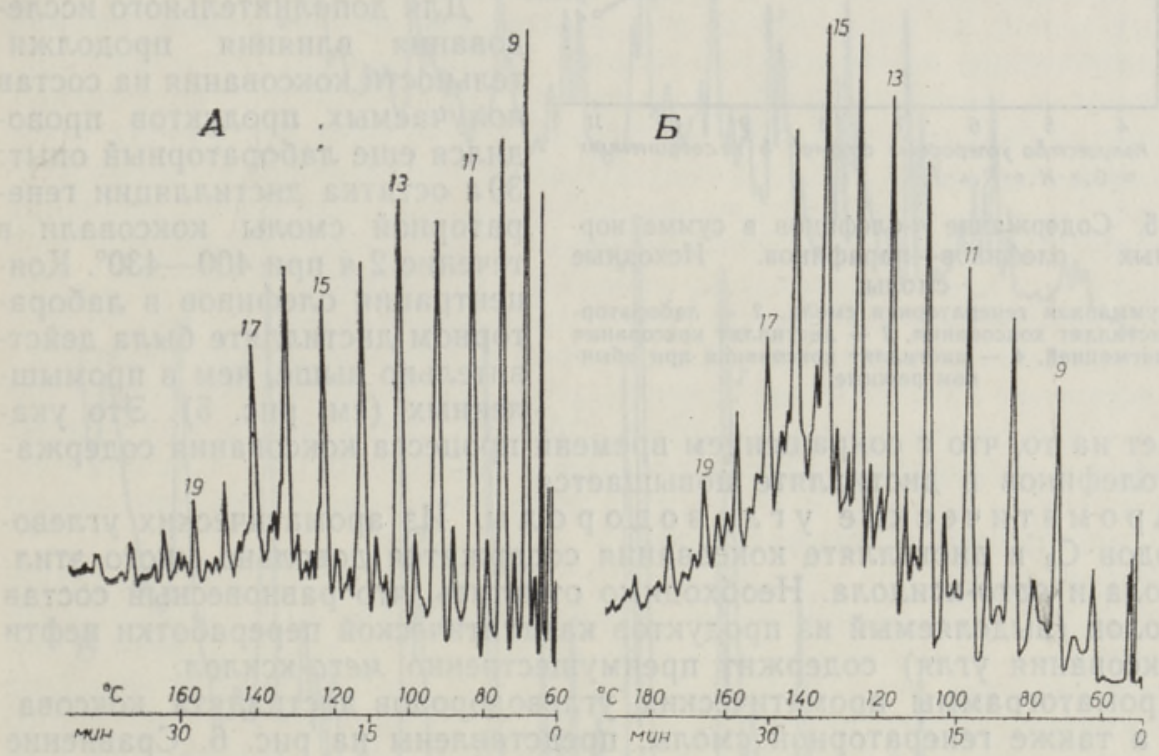

Рис. 4. Хроматограммы парафинов дистиллятов коксования.

$A$ - дистиллят при обычном режиме и 5 - дистиллят с дефлегмацией. Номера озна-

чают количество углеродных атомов в соответствующих $H$-парафинах.

П а р а фины. Хроматограммы парафинов приведены на рис. 4. Парафины дистиллятов коксования представлены почти полностью нор мальными соединениями, при этом содержание парафинов, имеющих в цепи более 17 атомов углерода, очень низко. По этой характеристике парафины ничем не отличаются от парафинов первичных смол $[4,10]$. В результате рецикла при коксовании содержание парафинов в дистилляте повысилось (см. таблицу), судя по. хроматограммам, особенно в области $\mathrm{C}_{13}-\mathrm{C}_{16}$, что указывает на преимущественное образование этих соединений при более глубоком разложении сырья.

О л е фи н ы. Реакционно-хроматографическим гидрированием [11] установлено, что олефины, как и парафины, имеют только прямолинейный углеродный скелет. Исследование изомерного состава олефинов показало, что олефины генераторной смолы и дистиллятов коксования состоят примерно на $2 / 3$ из 1 -нзомеров $\left[{ }^{12}\right]$.

Сравнение хроматограмм генераторной смолы и дистиллятов коксования (см. рис. 3) показало, что на последних пнки 1-олефинов очеңь низкие. Содержание олефинов в нормальных углеводородах представлено на рис. 5. Оказывается, что из нормальных углеводородов первичной генераторной смолы олефины составляют более $50 \%$, а из дистиллятов коксования - значительно меньше. Такое отличие установлено уже и ранее [']. Коксование сланцевой смолы проводится при относительно низкой температуре, продолжительность процесса более десяти часов, в присутствии водорода - все эти факторы направляют равновесную ре 


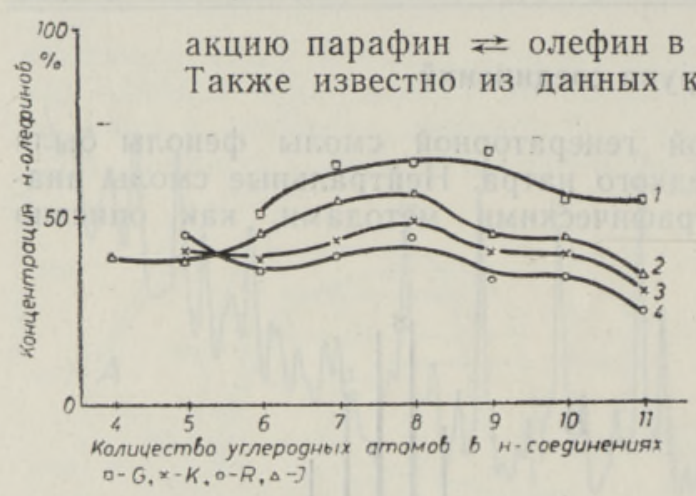

Рис. 5. Содержание н-олефинов в сумме нормальных олефинов-парафинов. Исходные смолы:

$t$ - суммарная генераторная смола, 2 - лаборатор. ный дистнллят коксовання, 3 - дистиллят коксования с дефлегмацией, 4 - дистиллят коксования при обыч ном режиме.

сторону образования парафина. оксования нефтяных продуктов $\left[{ }^{13}\right]$ и низкотемпературного швелевания сланца [14], что увеличение времени реакции повышает концентрацию парафинов в летучих продуктах.

Для дополнительного исследования влияния продолжи тельности коксования на состав получаемых продуктов проводился еще лабораторный опыт: 30 г остатка дистилляции генераторной смолы коксовали в течение 2 ч при $400-430^{\circ}$. Концентрация олефинов в лабораторном дистилляте была действительно выше, чем в промышленных (см. рис. 5). Это указывает на то, что с сокращением времени процесса коксования содержание олефинов в дистилляте повышается.

А ром атически е углеводо роды. Из ароматических углеводородов $\mathrm{C}_{8}$ в дистилляте коксования содержится довольно много этил бензола и орто-ксилола. Необходимо отметить, что равновесный состав ксплолов (выделяемый из продуктов каталитической переработки нефти и коксования угля) содержит преимущественно мета-ксилол.

Хроматограммы ароматических углеводородов дистиллята коксова ния, а также генераторной смолы, представлены на рис. 6. Сравнение хроматограмм показывает, что в днстилляте коксования содержание полициклических углеводородов немного выше, чем в первичной смоле. $\mathrm{Pe}$ цикл при коксовании еще повышает концентрацию незамещенных полициклических ароматических углеводородов. Содержание их метил- и диметилпроизводных также высоко.

Нейтральны е кислородные соединения. Кислородные соединения, выделенные колоночной хроматографией из дистиллятов коксования, разделили дополнительно тонкослойной хроматографией на структурные группы в зависимости от положения карбонильной группы в молекуле.

Установили, что в дистиллятах присутствуют алкилкетоны $\mathrm{C}_{6}-\mathrm{C}_{17}$. Результаты комплексного хроматографического анализа показали, что кетоны $\mathrm{C}_{6}-\mathrm{C}_{11}$ имеют преимущественно 2-карбонильную группу, а кетоны $\mathrm{C}_{13}-\mathrm{C}_{17}$ являются симметрическими диалкилкетонами. Концентрация 3-алканонов во всем диапазоне гомологических рядов стабильна н составляет $15-25 \%$ от суммы изомеров.

\section{Обсуждение результатов}

Еще несколько лет назад почти ничего не было известно о химическом составе и строении компонентов эстонской сланцевой смолы, кипящих выше $300^{\circ}$. Идентифицировано было только небольшое число полицик лических ароматических соединений. По общим показателям (например, высокая рефракция и удельный вес) считалось, что тяжелые фракции смолы состоят из ароматических кислородных соединений. Никто не подозревал в них присутствие длинных алкильных цепей. Первые сом 


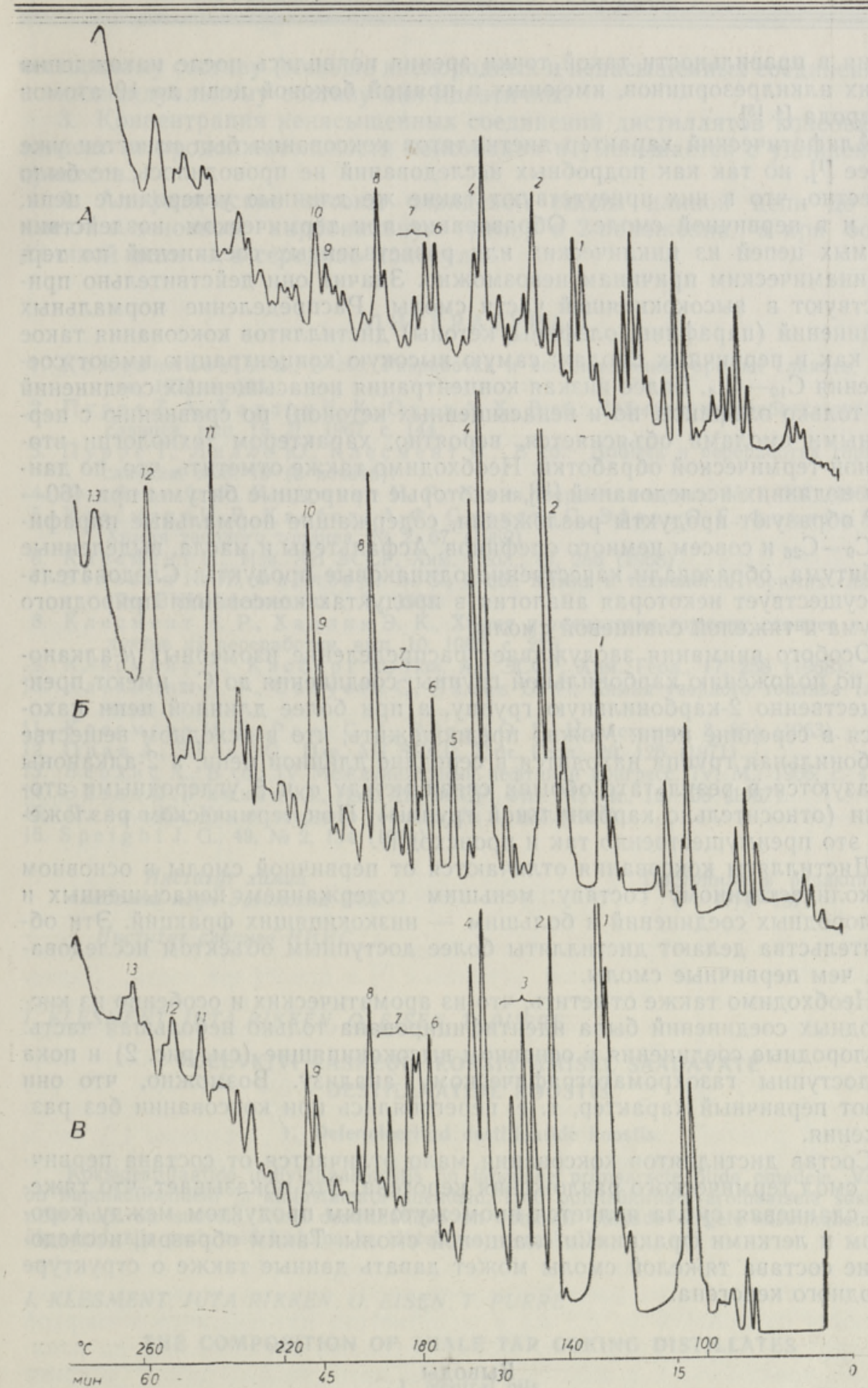

Рис. 6. Хроматограммы ароматических соединений.

$A$ - из дистиллята при обычном режиме, $B$ - из дистиллята с дефлегмациеи, $B$ - из генераторной смолы. Идентифицированные компоненты: $I$ - тетралин, 2 - нафталин, 3 метилтетралины, 4 - метилнафталины, 5 - дифенил, 6 - 2-этилнафталин, 7 - димелил. нафталины, 8 - аценафтен, 9 - флуорен, 10 - метилаценафтены, 11 - антрацен и фешзи. трен, I2 - метилантрацены и -фенантрены, 13-димегилантрацены и -фенантрень. 
нения в правильности такой точки зрения появились после нахождения в них алкилрезорцинов, имеющих в прямой боковой цепи до 10 атомов углерода [4, 15].

Алифатический характер дистиллятов коксования был известен уже ранее ['], но так как подробных исследований не проводилось, не было известно, что в них присутствуют такие же длинные углеродные цепи, как и в первичной смоле. Образование при термическом воздействии прямых цепей из циклических или разветвленных соединений по термодинамическим причинам невозможно. Значит они действительно присутствуют в высококипящей части смолы. Распределение нормальных соединений (парафины, олефины, кетоны) дистиллятов коксования такое же, как в первичных смолах: самую высокую концентрацию имеют соединения $\mathrm{C}_{10}-\mathrm{C}_{14}$. Более низкая концентрация ненасыщенных соединений (не только олефинов, но и ненасыщенных кетонов) по сравнению с первичными смолами объясняется, вероятно, характером технологии вторичной термической обработки. Необходимо также отметить, что, по данным недавних исследований [ $\left.{ }^{16}\right]$, некоторые природные битумы при 460 $470^{\circ}$ образуют продукты разложения, ссдержащие нормальные парафины $\mathrm{C}_{9}-\mathrm{C}_{26}$ и совсем немного олефинов. Асфальтены и масла, выделенные из битума, образовали качественно одинаковые продукты. Следовательно, существует некоторая аналогия в продуктах коксования природного битума и тяжелой сланцевой смолы.

Особого внимания заслуживает распределение изомерных $\boldsymbol{H}$-алканонов по положению карбонильной группы: соединения до $\mathrm{C}_{12}$ имеют преимущественно 2-карбонильную группу, а при более длинной цепи находятся в середине цепи. Можно предположить, что в исходном веществе карбонильная группа находится в середине длинной цепи, а 2-алканоны образуются в результате обрыва связи между $\alpha$ и $\beta$ углеродными атомами (относительно карбонильной группы). При термическом разложении это преимущественно так и происходит.

Дистилляты коксования отличаются от первичной смолы в основном по количественному составу: меньшим содержанием ненасыщенных и кислородных соединений и большим - низкокипящих фракций. Эти обстоятельства делают дистилляты более доступным объектом исследова ния, чем первичные смолы.

Необходимо также отметить, что из ароматических и особенно из кислородных соединений была идентифицирована только небольшая часть. Кислородные соединения в основном высококипящие (см. рис. 2) и пока не доступны газохроматографическому анализу. Возможно, что они имеют первичный характер, т. е. перегонялись прн коксовании без раз ложения.

Состав дистиллятов коксования мало отличается от состава первичных смол термического разложения керогена. Это показывает, что тяжелая сланцевая смола является промежуточным продуктом между керогеном и легкими фракциями сланцевой смолы. Таким образом, исследование состава тяжелой смолы может давать данные также о структуре исходного керогена.

\section{Выводы}

1. Тяжелая смола полукоксования является промежуточным продуктом термического разложения керогена. В ней присутствуют в большом количестве длинные углеродные цепи $\mathrm{C}_{14}-\mathrm{C}_{17}$.

2. Дистилляты коксования отличаются от первичных смол по коли- 
чественному составу (меньше кислородных и ненасыщенных соединений), по индивидуальному составу они идентичны.

3. Концентрация ненасыщенных соединений дистиллятов коксования зависит от продолжительности коксования и уменьшается с удлинением процесса.

4. Алифатические кетоны сланцевой смолы длиной цепи до $\mathrm{C}_{12}$ имеют в основном карбонильную группу в 2-положении, а при более длинной цепи - в середине молекулы

\section{ЛИТЕРАТУРА}

1. Ко жевников А. В., В сб.: Разработка и использование горючих сланцев, Таллин, 1970, с. 513.

2. Пур ре Т. А., Х а л ли к Е. К., О р а в А. Х., В сб.: Добыча и переработка горючих сланцев, вып. 16, Л., 1967, с. 144.

3. Пурре Т., Лилле Ю., Клесмент И., В сб.: Добыча и переработка горючих сланцев, вып. 19 (в печати).

4. К асберг А. Ф., Клесмент И. Р., Химия твердого топлива, № 1, 107 (1969)

5. Клесмент И. Р., Касберг А. Ф., Салусте С., Эйзен О. Г., Фоиина А. С., Химия твердого топлива, № 2, 67 (1969).

6. К лесм ен т И., Изв. АН ЭССР, Хим. Геол., 17, 285 (1968).

7. 3 еле н и н Н. Й., Ф айн бе рг В. С., В сб.: Химия и технология горючих сланцев (Тр. ВНИИНефтехима), Л., 1968.

8. Клесмент И. Р., Х алли к Э. К., Химия и технология горючих сланщев и продуктов нх переработки, вып. 10, 1962, с. 228.

9. Клесмент И., К а сберг А., Изв. АН ЭССР, Хим. Геол., 17, 258 (1968).

10. К лесмент И Р., С алусте С., Эйзен О. Г., Химия твердого топлива (в печати).

11. Клесмент И. Р., Р анг С. А., Эйзен О. Г., Нефтехимия, 3. 864 (1963).

12. О р а в А., Э й зен О., Изв. АН ЭССР, Хим. Геол., 20, 126 (1971).

13. В е р х и с А.. В сб.: IV Международный нефтяной конгресс, IV, М., 1955, с. 416.

14. Эй з е н О., Р и к ке н Ю., Изв. АН ЭССР, Физ. Матем., 16, 108 (1967).

15. Л и лл е Ю., Химия твердого топлива, № 4, 107 (1969).

16. S peight J. G., 49, № 2, 134 (1970).
Институт химии
Академии наук Эстонской ССР
Поступила в редакцию

Ннститут сланцев НИИС

\section{KLESMENT, JUTA RIKKEN, O. EISEN, T. PURRE}

\section{POLEVKIVI RASKEOLI KOKSISTAMISEL SAADAVATE DESTILLAATIDE KOOSTIS}

\section{Defenoleeritud destillaatide koostis}

Koksidestillaatide individuaalkoostis on lähedane primaarsete ōlide omadele. Vähem on hapnikuühendeid ja küllastamata ühendeid, kuid polütsükliliste aromaatsete süsivesi nike hulk on suurem. Kuna destillaatides on rohkesti pikkade sirgete süsinikahelatega ühendeid, siis peab neid leiduma ka lähteaines - raskeõlis.

\section{KLESMENT, JUTA RIKKEN, O. EISEN, T. PURRE}

\section{THE COMPOSITION OF SHALE TAR COKING DISTILLATES}

\section{Neutral oils}

The individual composition of coking distillates is similar to that of primary oils. The quantity of oxygen and unsaturated compounds is less, but that of the polycyclic aromatic hydrocarbons is higher. Since the distillates are rich in compounds with a long unbranched hydrocarbon skeleton, the same structural elements must be present in initia! material - high boiling tar, as well. 